\title{
Prostatic Burkitt Lymphoma, a Rare Secondary Location
}

\section{Adrien Mougougou ${ }^{1}$, Steevy Ndang Ngou Milama1, Smith Giscard Olagui ${ }^{2}$, Jean Massandé Mouyendi ${ }^{1}$}

${ }^{1}$ Urology Department, University Hospital Center of Libreville, Libreville, Gabon

${ }^{2}$ General Surgery and Urology Department, Instructions Hospital of the Armies Omar Bongo Ondimba, Libreville, Gabon

Email: *mougougouadrien@yahoo.fr

How to cite this paper: Mougougou, A. Milama, S.N.N., Olagui, S.G. and Mouyendi, J.M. (2021) Prostatic Burkitt Lymphoma, a Rare Secondary Location. Open Journal of Urology, 11, 226-231.

https://doi.org/10.4236/oju.2021.116020

Received: March 27, 2021

Accepted: June 25, 2021

Published: June 28, 2021

Copyright $\odot 2021$ by author(s) and Scientific Research Publishing Inc. This work is licensed under the Creative Commons Attribution International License (CC BY 4.0).

http://creativecommons.org/licenses/by/4.0/

\section{cc) (i) Open Access}

\begin{abstract}
Introduction: Non-Hodgkin's malignant lymphoma is found primarily in African children. Prostate localization is a rare entity. We report the case of a secondary prostatic localization of Burkitt lymphoma in a 14-year-old child. Observation: the 14-year-old child NNJ was followed at the Libreville Cancer Institute (ICL) for Burkitt maxillo-facial stage II bilateral Murphy lymphoma. The clinical examination noted an alteration of the general state, total hematuria, a voluminous prostatic mass filling the rectal ampoule. The paraclinical assessment noted renal insufficiency, a prostatic mass on ultrasound. Anatomo-pathological examination of the prostatic biopsy diagnosed Burkitt type non-Hodgkin's malignant lymphoma. He died a week later. Conclusion: Primary or secondary prostatic lymphoma is rare. Obstructive renal insufficiency is an additional complication that darkens its prognosis by delaying etiological treatment based on polychemotherapy.
\end{abstract}

\section{Keywords}

Burkitt Lymphoma, Prostate, Renal Insufficiency, Libreville

\section{Introduction}

Described in 1958 by Denis Parsons Burkitt, non-Hodgkin's malignant lymphoma is found mainly in African children with a peak in frequency between 6 and 7 years [1]. It can be divided into three subtypes: endemic, sporadic and associated with immunodeficiency [2]. The endemic type is almost always associated with the Epstein-Barr virus (EBV) and occurs frequently in African children. In western countries, the sporadic form is more common. The type associated with immunodeficiency is observed in patients infected with HIV [2]. 
Prostatic involvement is a rare entity and represents less than $0.1 \%$ of genitourinary involvement, most often associated with extraprostatic involvement [3] [4]. The specific treatment is based on polychemotherapy with anthracycline (Except in case of renal insufficiency) and radiotherapy, the place of surgery is reserved to support the diagnosis and in case of testicular involvement [5]. Burkitt's cure rates are higher than $95 \%$ in children and $80 \%$ in adults [3]. A review of the literature reports the poor prognosis of prostatic lymphoma, diagnosis often being late [6]. We report the case of a secondary prostatic localization of Burkitt lymphoma in a 14 -year-old child.

\section{Observation}

The 14-year-old NNJ child was referred from the Libreville Cancer Institute for total hematuria associated with dysuria, nocturnal pollakiuria and hypogastric pain. He was being followed to ICL for Burkitt maxillo-facial stage II bilateral Murphy lymphoma. We have not found a history of infectious mononucleosis and identification of the Epstein-Barr virus. He had 6 courses of chemotherapy containing cyclophosphamide, vincristine, doxorubicin and prednisone. Melting of the maxillofacial masses had made it possible to declare him in complete remission 6 months before, despite the absence of a PET scan. The clinical examination noted an alteration of the general state, a voluminous, hard, irregular and painful prostatic mass. The paraclinical assessment summarized in Table 1 noted renal insufficiency with severe hyponatremia, a large prostatic mass of $101 \times 83$ $\mathrm{mm}^{2}$ with bilateral uretero-hydronephrosis on ultrasound (Figure 1(a) and Figure 1(b)). The PSA rate was normal. Anatomo-pathological examination of the prostatic biopsy diagnosed Burkitt type non-Hodgkin's malignant lymphoma. Histological images (Figure 2 and Figure 3) with haematoxylin eosin examination showed a tumor proliferation of basophilic malignant cells within fibrous tissue with a so-called "starry sky" appearance.

Table 1. Laboratory parameters of a patient admitted for secondary prostatic lymphoma.

\begin{tabular}{cc}
\hline Additional Examination & Result \\
\hline Creatinine & $1528.2 \mu \mathrm{mol} / \mathrm{L}$ \\
Creatinine clearance & $5.4 \mathrm{~mL} / \mathrm{min}$ \\
Urea & $46.6 \mathrm{mmol} / \mathrm{L}$ \\
Blood sugar & $5.8 \mathrm{mmol} / \mathrm{L}$ \\
Natremia & $117 \mathrm{mEq} / \mathrm{L}$ \\
Kalaemia & $4.8 \mathrm{mEq} / \mathrm{L}$ \\
Chloremia & $92 \mathrm{mEq} / \mathrm{L}$ \\
hemoglobin & $13.1 \mathrm{~g} / \mathrm{dL}$ \\
CRP & $70 \mathrm{mg} / \mathrm{L}$ \\
PSA & $0.8 \mathrm{ng} / \mathrm{mL}$
\end{tabular}




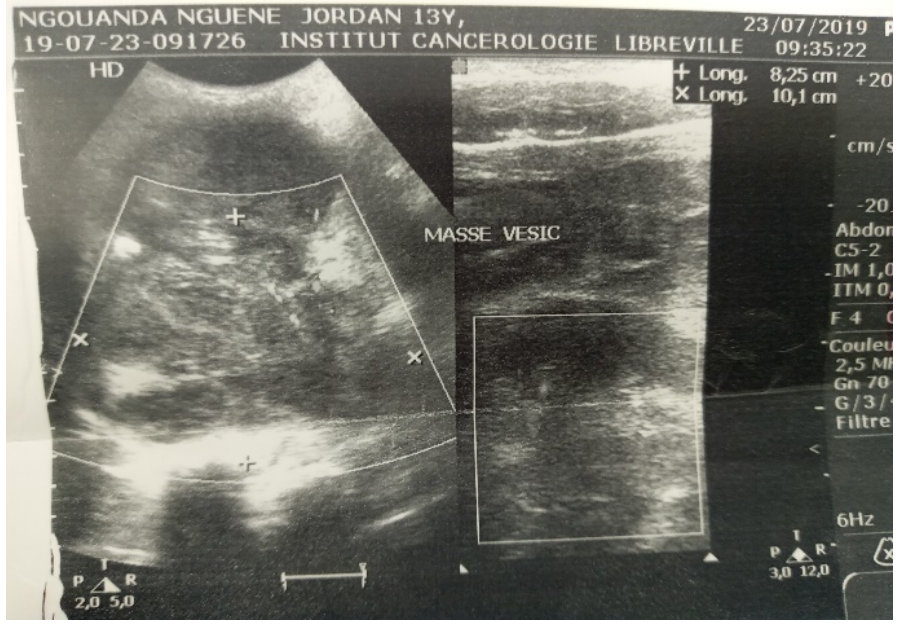

(a)

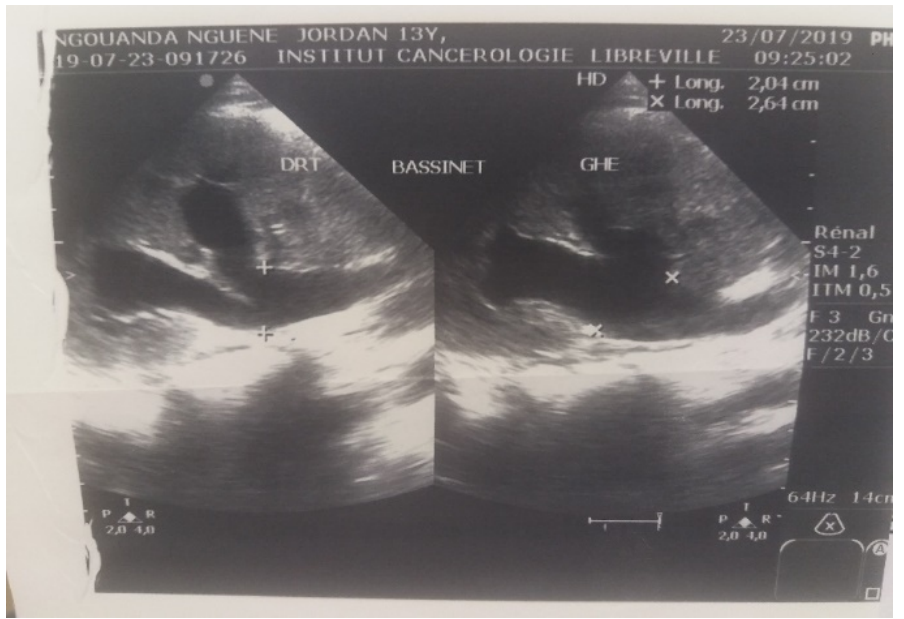

(b)

Figure 1. (a) and (b) Vesico-prostatic tumor mass of $101 \times 83 \mathrm{~mm}^{2}$ with bilateral uretero-hydronephrosis.

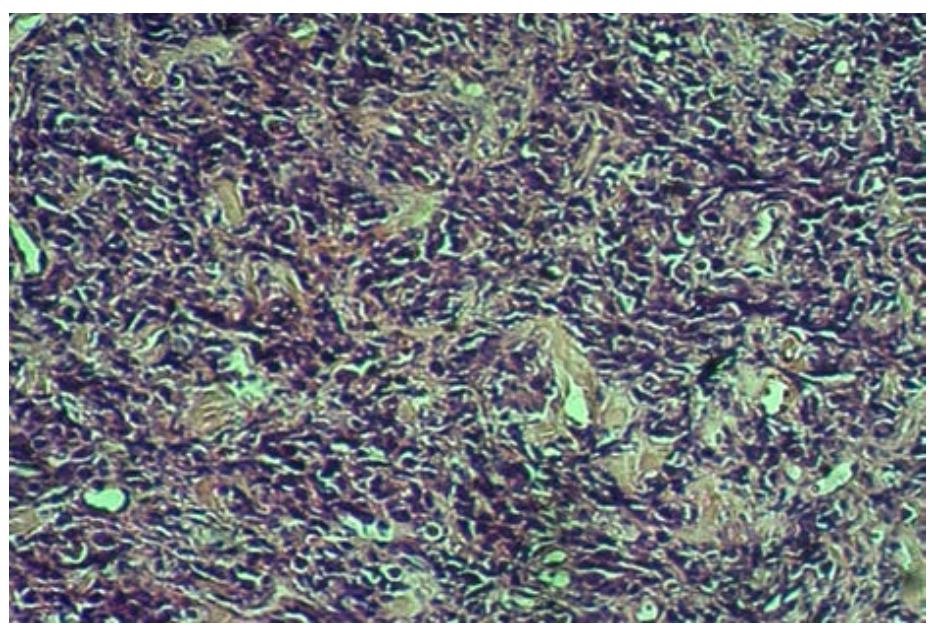

Figure 2. Histological image with eosin hematoxylin at low magnification $10 \times$ which shows tumor proliferation within a collagen fibrous tissue giving a "starry sky" appearance. 


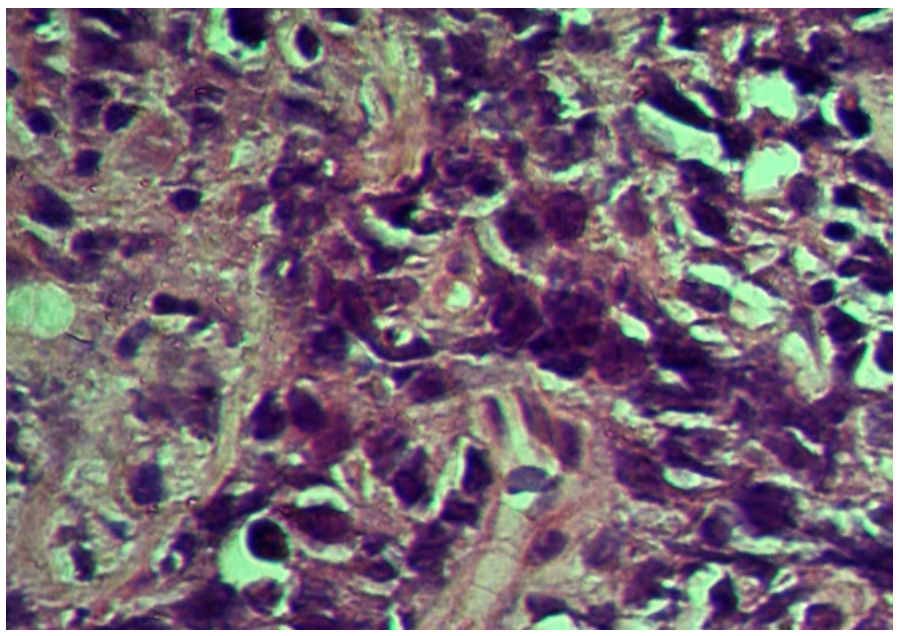

Figure 3. Histological image with eosin hematoxylin at high magnification $40 \times$ showing a proliferation of malignant, basophilic lymphoid cells with tingible bodies macrophages giving a "starry sky" appearance.

The patient had been probed with bladder irrigation. He was on antibiotics (ceftriaxone), haemostatic (tranexamic acid), analgesic (paracetamol) and prednisone. He had also 3 hemodialysis sessions. He died one week later in intensive care with a non-febrile seizure while waiting for his kidney function to improve before starting new chemotherapy sessions.

\section{Discussion and Comments}

WHO characterizes Burkitt lymphoma in 3 types: endemic, sporadic and associated with immunodeficiency [7]. Renal involvement is the most common of all the urogenital tract and represents the second extra-lymph node location of lymphomas after the lung followed by testicular involvement in the elderly [7]. Vesical and prostatic locations are very rare and their incidence is poorly known [7]. Indeed, non-Hodgkin's lymphomas, which include Burkitt's lymphoma, affect the prostate in only $0.1 \%$ of cases [4]. They most often present as painless lymphadenopathy elsewhere in the body and can cause abdominal or chest pain and systemic symptoms such as fever, weight loss and night sweats [4]. This symptomatology was present in our patient, including abdominal pain, profuse sweating and a deterioration in general condition.

Our 14-year-old case had obstructive urination disorders and primary maxillary localization of Burkitt's lymphoma. It looks like the one described by Sinclair et al. [8] who had concurrent maxillary and prostatic involvement. However, this localization remains rare because, according to these radiologists, although abdominal and pelvic lesions are common, prostatic Burkitt's lymphoma, especially in children, would not have been previously described in the imaging literature [8].

In a multi-institutional study of 62 malignant lymphoma cases involving the prostate, Bostwick et al. [9] reported a single case of Burkitt lymphoma described in the only child in the series. He is a 5-year-old boy with secondary prostate 
disease who died a week after diagnosis. In this report of 62 cases of malignant lymphoma affecting the prostate, mainly in adults, they found that secondary prostate involvement was more frequent than primary involvement (65\% versus $35 \%$ ) and that lymphoma-specific survival was $64 \%$ at 1 year and $50 \%$ at 2 years. The case we are reporting is the first observed in our service since it's opened for thirty years. This confirms the rarity of this location.

Only ultrasound had allowed us to explore the prostate. Specific imaging of the prostate is rarely justified in children but is included in the assessment of symptoms related to the lower genitourinary tract, including urinary retention, hematuria, dysuria and incontinence, or during investigations for suspected congenital abnormalities [8]. If benign vesicoprostatic causes are excluded or if treatment fails, broader diagnostic tests such as cystoscopy and imaging techniques such as computed tomography or MRI are required. A subsequent prostate biopsy must be performed urgently to clarify the diagnosis [4]. Cystoscopy and prostate biopsy did allow us to make the diagnosis of Burkitt's lymphoma in our case. According to Humphrey et al. [10], in younger patients, malignant rhabdomyosarcomas are the most common prostate malignancy and there are only a few reports of childhood prostate Burkitt lymphoma. Renal failure delayed the treatment of our patient who died a week after making the diagnosis of secondary prostatic localization of Burkitt's lymphoma. According to Ferry [2], in recent years, Efforts that focused on improving therapy led to the development of combined short-term chemotherapy proven to be extremely effective for a high proportion of patients with Burkitt's lymphoma. The specific treatment is based on polychemotherapy with anthracycline (Except in case of renal insufficiency) to radiotherapy, the place of surgery is reserved to support the diagnosis and in case of testicular involvement [7]. The prognosis is poor and related to age, histology and tumour grade. The specific survival of these lymphomas is $75 \%$ at one year, $50 \%$ at 2 years, $33 \%$ at 5 years and $16 \%$ at 15 years. The median survival is identical between primary and secondary lymphomas (28 months). This poor prognosis is reported by Ghoundale et al. [6] who noted that despite a considerable regression in tumour volume from the third week onwards, the patient died the day after his 5th cycle of chemotherapy. Renal insufficiency was therefore a limiting factor in the initiation of the ideal treatment in our patient. This renal insufficiency associated with the therapeutic delay induced by this complication certainly worsened the vital prognosis in our case.

\section{Conclusion}

Primary or secondary prostatic localization of Burkitt's lymphoma is rare. Obstructive renal insufficiency is an additional complication that darkens its prognosis by delaying etiological treatment based on polychemotherapy.

\section{Conflicts of Interest}

The authors declare no conflicts of interest regarding the publication of this paper. 


\section{References}

[1] Burkitt, D.A (1958) A Sarcoma Involving the Jaws in African Children. The British Journal of Surgery, 46, 218-223. https://doi.org/10.1002/bjs.18004619704

[2] Ferry, J.A. (2006) Burkitt's Lymphoma: Clinicopathologic Features and Differential Diagnosis. The Oncologist, 11, 375-383.

https://doi.org/10.1634/theoncologist.11-4-375

[3] Chargari, C., Gillion, N., Ghalibafian, M., Ribrag, V., Girinsky, T. and Magné, N. (2009) Un cas rare de lymphome B diffus primitif de la prostate et revue de la littérature. Cancer/Radiothérapie, 13, 69-71. https://doi.org/10.1016/j.canrad.2008.08.280

[4] Derigs, M., Pehl, A., Riera-Knorrenschild, J., Hofmann, R. and Hegele, A. (2020) Burkitt's Lymphoma of the Prostate Presenting as Acute Urinary Retention: A Case Report. BMC Urology, 20, Article No. 53. https://doi.org/10.1186/s12894-020-00616-3

[5] De Fromont, M., Xerry, L. and Coulange, C.(2000) Les lymphomes en urologie dans “Tumeurs rares en Urologie”. Progrès en Urologie, 10, 93-100.

[6] Ghoundale, O., Deligne, E., Camparo, P., N’Diaye, A., Desfemmes, F.R. and Houlgatte, A. (2009) Le lymphome primitif de la prostate: à propos d'un cas avec revue de la littérature. African Journal of Urology, 15,148-153. https://doi.org/10.1007/s12301-009-0024-5

[7] Biko, D.M., Anupindi, S.A., Hernandez, A., Kersun, L. and Bellah, R. (2009) Childhood Burkitt Lymphoma: Abdominal and Pelvic Imaging Findings. American Journal of Roentgenology, 192, 1304-1315. https://doi.org/10.2214/AJR.08.1476

[8] Sinclair, N., Babyn, P., Kinloch, M. and Sinha, R. (2014) A Rare and Unusual Case of Burkitt's Lymphoma Presenting with a Prostate Mass in a 12-Year-Old Boy. Case Report in Radiology, 2014, Article ID: 106176. https://doi.org/10.1155/2014/106176

[9] Bostwick, D.G., Iczkowski, K.A., Amin, M.B., Discigil, G. and Osborne, B. (1998) Malignant Lymphoma Involving the Prostate: Report of 62 Cases. Cancer, 83, 732-738. https://doi.org/10.1002/(SICI)1097-0142(19980815)83:4<732::AID-CNCR15>3.0.C $\underline{\mathrm{O} ; 2-\mathrm{T}}$

[10] Humphrey, P.A., Moch, H., Cubilla, A.L., Ulbright, T.M. and Reuter, V.E. (2016) The 2016 WHO Classification of Tumours of the Urinary System and Male Genital Organs-Part B: Prostate and Bladder Tumours. European Urology, 70, 106-119. https://doi.org/10.1016/j.eururo.2016.02.028 